\title{
THE SCHOOL-BASED SPEECH-LANGUAGE THERAPIST: CHOOSING MULTICULTURAL TEXTS
}

\author{
Saloshni Moodley, Sandhya Chetty \& Jenny Pahl \\ Disciplines of Audiology and Speech-Language Pathology \\ School of Therapeutic and Rehabilitative Sciences \\ University of KwaZulu-Natal
}

\begin{abstract}
School-based speech-language therapists have a pivotal role in the transformation of education as directed by current education policy. The Revised National Curriculum Statement, for example, foregrounds a multicultural perspective in education, which impacts on the choice of Learning and Teaching Support Materials. Inappropriate support materials could create barriers to learning. Folktales were selected as an example of multicultural Learning and Teaching Support Materials. The responses of 10-year-old mainstream learners to five folktales reflecting a diversity of cultures were explored. Five girls and five boys in Grade 5 participated in the study, which was conducted in three phases. A questionnaire, a focus group interview, and audio-visual recordings were used to gather data. The qualitative method of constant comparison was used to analyse emerging themes. Five main themes were identified. Findings revealed that some participants responded most positively when folktales reflected their culture, gender, or physical characteristics. Participants' views on less familiar cultures were influenced by the mass media. The results highlighted the importance of the text as 'mirror' and as 'window'. The potential of folktales as multicultural Learning and Teaching Support Materials, the powerful influence of the educator on learners' responses, and the need for an anti-bias approach within education are discussed. Implications for future research and practice are highlighted.
\end{abstract}

Key words: speech-language therapist, educator, cultural diversity, folktales, multicultural learning and teaching support materials, barriers to learning, anti-bias approach

\section{INTRODUCTION}

The Department of Education employs a number of speech-language therapists to render speech and language therapy services within schools. These speech-language therapists are regarded as educators and registration with the South African Council of Educators (SACE) is mandatory. An 'educator' is defined as "any person... who provides professional educational services, including professional therapy... at an institution" (Education Labour Relations Council [ELRC], 2003, p. E3). Within this article, the term 'educator' therefore refers collectively to the speech-language therapist and the teacher.

A number of policy documents seek to transform the South African education system into one that is unbiased, inclusive, and multicultural. At present, the most pertinent documents are Education White Paper 6 on Special Needs Education (Department of Education, 2001) and the Revised National Curriculum Statement Grades R-9: Schools (Department of Education, 2002a). The principles espoused in these documents present a challenge to all schools and educators to change their thinking and their practice. While the Revised National Curriculum Statement (RNCS) outlines a multicultural curriculum for grades $\mathrm{R}$ to nine, Education White Paper 6 is focused on restructuring the current dual system of education, which segregates learners on the basis of disability. At present, learners who are identified as having.special educational needs (e.g. physical disabilities; specific learning difficulties) are removed from the mainstream sector and placed within 'special schools'. Thus only a small percentage of leamers are receiving specialised support and education (Department of Education, 2001). The White Paper, however, acknowledges that all learners need support, and hence support should be provided in all classrooms to ensure the full participation of all learners. It has therefore introduced a key shift away from focussing on the intrinsic problems of learners, to identifying and minimising barriers to learning.

A barrier to learning is anything that hinders the learning and development of a learner. Such barriers could thus be societal (e.g. poverty), systemic (e.g. an inflexible curriculum), or located in the leamer (Department of Education, 2001). Educators are expected to fulfil the important responsibility of addressing barriers to learning when implementing the RNCS. This implies that the classroom environment, teaching strategies, and Learning and Teaching Support Materials, for example, must be adjusted to respond to learner diversity within every classroom. This transformation, which is needed so that the existing resources can be used optimally (Department of Education, 2001), has implications for the present role of the school-based speechlanguage therapist.

Within an inclusive education system, the speechlanguage therapist will have a consultative and collaborative role in district-based and institution (school)-based support teams (Department of Education, 2001). Support has been redefined in the White Paper to encompass training, mentoring, monitoring, and consultation. As part of the support team, the speechlanguage therapist will help to develop strategies to identify and manage barriers to learning at learner, educator, curriculum, and institutional levels (Department of Education, 2001). They also have a responsibility to interpret the RNCS, as it is pertinent to their redefined role in curriculum delivery.

A perusal of the RNCS reveals that the speech-language therapist would be most involved with curriculum delivery within the Literacy Learning Programme, which focuses on language acquisition, language development, and communication. It has been well documented that reading or telling stories to children within the home and the classroom promotes language development (Champion, Katz, Muldrow, \& Dail, 1999; Galda, Ash, \& 
Cullinan, 2001; Owens \& Robinson, 1997). Story reading can also be used as an intervention tool (Champion et al., 1999; Owens \& Robinson, 1997) to improve listening skills, vocabulary, literacy skills, language comprehension, and verbal expression (Owens \& Robinson, 1997). Furthermore, the RNCS acknowledges that "listening to stories is also part of the foundation for literacy" (Department of Education, 2002c, p. 9). Thus an integral part of one's role as a school-based speech-language therapist could be the use of story reading to address the needs of multiple learners in the classroom. Within such a Learning Programme, sharing children's literature with the learners would involve much more than merely reading aloud. Rather, it would be an interactive process where the speech-language therapist would facilitate each learner's participation and comprehension by asking and answering questions, responding to the learners' comments, and relating learners' responses to their life experiences.

While it is important to consider how children's literature would be used within the classroom, it is also pertinent to reflect on what type of literature would be selected. Booysen (1996) claims that reading aloud to children within the classroom gives educators the opportunity "to introduce children to quality literature" and enables children "to recognise that reading good literature is something which adults prize" (p.411). It can be argued that the type of literature that one would regard as "quality or good literature' would be strongly influenced by the one's personal preferences. According to Outhwaite (1994) school-based literacy in South Africa continues to reflect Western middle class values, beliefs, and norms. This implies that Anglo-centred literature and the English language are valued (Lemmer, 1996). Given the linguistic and cultural diversity of leamers and the multicultural perspective promoted by the RNCS, choosing literature that continues to reinforce Anglo-centred cultures could act as a significant barrier to learning.

Research has shown a strong link between culture and learning (Nieto, 1996). Learners who do not see a reflection of themselves in their schooling may feel that they are not valued by the educator, the school, or society (Montgomery, 2001). Learners may become dissociated and resistant towards a curriculum that alienates them (Gardner, 2001) which may impact negatively on their school performance. Furthermore, cultural identity serves an important function in people's lives as it facilitates a sense of peoplehood (Schultz, 1995) and enables the individual to answer the question "Who am I?" All educators must acknowledge that they direct learners towards particular actions, values, and language, through the learning materials (e.g. stories) they present in the curriculum. Thus there is a pressing need for a transformation to a multicultural perspective as cultural dissonance between the school and culturally diverse learners could create a barrier to learning.

The term 'culture' refers to the values, beliefs, and behaviours, traditions, symbols and ideas that are shared by a group of people (Kavanagh \& Kennedy, 1992; Locke, 1992). It includes explicit features (e.g. language and dress) and implicit features such as attitudes and family relationships (Kavanagh \& Kennedy, 1992; Locke, 1992; Nieto, 1996). The term 'multicultural' therefore encompasses the diversity of cultures or subcultures that exist within a given society. As Ford (1999) states: “... a multicultural perspective indicates a transformational change from the dominant Eurocentric perspective shaped through socialization... to an inclusive view of multiple perspectives and multiple realities" (p. 14). Advocates of multiculturalism in schools support the inclusion of multiple perspectives and an attitude of social justice within education (Willis \& Johnson, 2000). They believe that this will enrich education and enable learners to understand issues related to difference, dominance, power and privilege (Locke, 1998). These beliefs are fundamental to the RNCS.

Both Education White Paper 6 and the RNCS emphasise that educators have a responsibility to accommodate and manage diversity by providing a flexible curriculum that can be accessed by all learners. While it is acknowledged that the educator has to review all aspects of the curriculum for a multicultural perspective, the focus of the discussion is on the learning support materials (viz. stories) used within the curriculum. The discussion has emphasised that a bias towards Learning and Teaching Support Materials that reflect only Anglo-Saxon English-speaking cultures, would encourage learners to view the world from only one perspective. It would exclude the multiple realities and perspectives of learners. The educator has an important role in fostering the leamer's thinking about literature, culture, and diversity (Althanases, 1998). By carefully selecting the literature that is used as Learning and Teaching Support Materials, speechlanguage therapists could provide learners with opportunities to view or take part in the lives of people from diverse cultures and with different or similar life experiences.

A number of authors (Bieger, 1996; Gillespie, Powell, Clements, \& Swearingen, 1994; Sims Bishop, 1992) have highlighted multicultural literature as a valuable tool in providing multiple perspectives within the curriculum. Gillespie et al. (1994) have pointed out that multicultural literature has an important role to play in developing three perspectives that are pertinent to a multicultural society. Multicultural literature can show us how we are connected through common experiences, needs, and desires; it can help us to celebrate the cultural differences that enrich society, and it can help us to understand how social and political forces affect our lives. These outcomes are closely linked to the overall contribution of the Languages Learning Area to the curriculum, namely, to encourage "intercultural understanding, access to other views, and a critical understanding of the concept of culture" (Department of Education, 2002b, p. 7). Thus educators need to make informed choices about the types of multicultural literature that would be appropriate as Learning and Teaching Support Materials.

'Multicultural literature' refers to literature such as stories, poems, prose, and plays that reflect the multiple values, experiences, and perspectives of various cultural groups. Taylor (2000) describes multicultural literature as literature that focuses on people whose histories, contributions, and identities have been undervalued, distorted, or omitted in the school curriculum and society. Any 'multicultural literature programme' should reflect the principles of inclusiveness and the deconstruction of stereotypes. The speech-language therapist who wishes to function within the tenets of the South African Department of Education (2002b) needs to examine which type of storybooks with multicultural themes would be a suitable vehicle for the promotion of multicultural awareness and understanding.

The RNCS (2002b) echoes views stated in the literature that educators have to provide learners with opportunities to make connections, and to celebrate the differences and similarities among humans (Sims Bishop, 1992). Using stories about different cultures, it is believed, will facilitate tolerance and understanding (Booysen, 1996). Folktales have been recommended as a good springboard (Booysen, 1996) for discussions about different cultures as they are said to be reflective of their culture of origin (Bieger, 1996; Sims Bishop, 1992). It has been suggested that all children enjoy folktales or stories set in other cultures and times (Wade, 1990, cited in Booysen, 1996). Folktales are fictional sto- 
ries that do not have a particular location in space or time, and either concern royalty or common people, or animals behaving like people (Rosenberg, 1997). They are ideal for 'read-alouds' because they originate from the oral tradition (Bieger, 1996).

There is an extensive body of research that investigates learner response to multicultural literature in linguistically and culturally diverse classrooms (Althanases, 1998; Galda et al., 2001; Jordan \& Purves, 1993; Naidoo, 1992; Webster, 2001; Willis \& Johnson, 2000). These researchers used multicultural literature that was either overtly inter-racial, depicting diverse children interacting with each other, or that aimed to show how to cope with racism and discrimination. Stories like folktales, which do not focus on integration but aim to show the distinctive experience of belonging to a specific cultural group (Sims Bishop, 1992), were not used. The studies mentioned above focussed on the responses of high school learners in the USA and Britain. Thus there is a paucity of research on learners' responses to folktales even though folktales have been described as a rich source for developing understanding about cultural diversity. There also appears to be a lack of South African studies and a lack of studies using primary school learners. Consequently, there is a need to explore the phenomenon of learners' responses to folktales as one type of multicultural literature. The purpose of this study was therefore to explore primary school children's responses when folktales reflecting a diversity of cultures were read to them. The findings would contribute to the body of knowledge available on children's responses to culturally diverse literature. Based on her research findings, Saccardi (1994) proposed that children's responses to books could enable educators to make wise choices when selecting books for use with children. Thus the information from the present study could inform educators on how best to handle multicultural practice and how to address possible barriers to learning within the curriculum.

\section{METHODOLOGY}

\section{Aim}

To explore the responses of a group of ten-year-old learners within mainstream education when folktales reflecting a diversity of cultures were read to them.

Critical questions. What were the participants' responses to the folktales? Why did the participants have these responses to the folktales?

\section{Research Design}

In the study, the term 'response' included written and spoken responses, spontaneous responses such as laughter, and non-verbal responses such as nodding to show agreement or shrugging as a sign of doubt or indifference. A qualitative approach best enabled the researcher to gather data that represented 'responses' as defined in this study. Researchers using a qualitative approach gather data, in the form of written or spoken language, by interacting personally (Pidgeon, 1996) with participants. They attempt to understand or discern phenomena "in terms of the meanings people bring to them" (McMillan \& Schumacher, 2000, p.395). The present researcher supports the interactive nature of qualitative research where the researcher interacts with each participant as an individual. This interaction closely resembles the relationship between the educator and the learner. Furthermore it is deemed 'good practice' for researchers to provide clarification of their methodological stance, as it is believed that the researcher's ideology influences the research. The present researcher agrees with Denzin and Lincoln (1998) that qualitative research is a multicultural process because it is shaped by the gender, racial, ethnic, and cultural perspective of the researcher. Denzin and Lincoln also stress the intimate relationship between the 'multiculturally situated researcher' and the focus of the research. In addition it is crucial for the researcher to understand the political and socio-cultural dynamics of the research context because such dynamics also impact on the data collected within that context. It is within these beliefs that the study attempted to describe and explore learners' responses to culturally diverse folktales.

The research design for the study was based on Grounded Theory (Glaser \& Strauss, 1967, as cited in Pidgeon, 1996). A grounded theory research design has certain distinguishing characteristics. The data collection and analysis phases of the research occur simultaneously. The researcher can move between the two phases and the emerging analysis shapes the data collection procedures. The researcher creates analytic codes and develops categories from the data, not from preconceived concepts. Furthermore there are specific methods of data analysis available to the researcher, for example, constant comparison and theoretical sampling (Pidgeon, 1996).

Based on the characteristics of a grounded theory research design mentioned above, the present study was originally structured into two phases. During Phase 1, four folktales were read aloud to the participants and the participants answered a questionnaire about their responses to each folktale. Phase 2 consisted of a focus group interview. Based on the data that emerged during Phase 1 , a third phase was added to enable the researcher to collect more data on emerging questions and themes. This change is in keeping with the flexible nature of a grounded theory research design, which enables the researcher to collect additional data and follow up on questions.

\section{Research Site}

The site in question was an urban primary school catering for mainstream learners and learners with special educational needs (LSEN). The site was selected because the population of learners at the site represents a cross section of learners in terms of socio-economic status, race, culture, and language. Furthermore, the results would inform the researcher's understanding of how the educational policies regarding multiculturalism and literacy may be applied to the practice of Speech-Language Therapy within education.

\section{Participants}

Participants had to be ten-year old, fifth grade 'mainstream' learners at the research site. Research by Lemmer (1988) and Sims (1983) showed that it was possible to successfully interview ten-year old learners on their responses to storybooks. There is also a paucity of research with this age group (Sims, 1983). Ten-year olds were therefore selected for the study. Learners in mainstream Grade 5 classes were selected because the Department of Education (2002b; 2002c) highlighted that learners in Grade 5 can be expected to ask and réspond thoughtfully to critical questions that do not have obvious answers; to express and justify their own opinions with reasons; and to understand how interviews work as a means of obtaining information. The teachers of the Grade 5 classes were asked to identify learners who would be able to follow grade-appropriate instruc- 
tions, read a questionnaire and record answers legibly, and participate in a group interview, all within the medium of English. LSEN were excluded as their specific difficulties with receptive, expressive, and written language would affect their ability to read the questionnaire, record their answers in writing, and express themselves verbally during the focus group interview.

Naidoo (1992) found that the girls in her study responded more frequently during small group discussions than whole class discussions. In light of Naidoo's finding and considering that the sample in the present study would need to be of a manageable size for the focus group interview in Phase 2, the researcher decided that a sample of 10 learners would be appropriate for the study. Furthermore, an equal number of boys and girls were needed to control for possible gender bias. The subsequent list of names identified by the teachers was divided into two groups according to gender. Five girls and five boys were randomly selected from these groups. All the learners who had been selected were willing to participate in the study and written informed consent was obtained from their parents, See Appendix A for a profile of the participants.

\section{Folktales}

The folktales had to fulfil the general criteria for authentic and accurate multicultural literature outlined in Appendix B. Webster (2001) pointed out that similarities between the cultural backgrounds of the participants and the texts might hinder the participants from 'entering the story'. Thus the researcher wished to minimise participant discomfort and enable each person to respond and comment without feeling that his or her culture was being criticised. Folktales that were culturally, historically, and geographically distant to the participant and that did not mirror the culture of any specific participant were therefore deemed suitable for this study. The folktales had to highlight the theme of family relationships, which are an implicit feature of the concept of culture (Locke, 1992). Four folktales, from Russia, China, Czechoslovakia, and Cambodia were selected. These folktales were distant to the cultures of all participants and were read to them during Phase 1.

\section{Data Collection Instruments}

A questionnaire schedule (Appendix D) and an interview schedule (Appendix E) were used to collect the data. The questionnaire schedule comprised a total of nine questions, with both open-ended questions and dichotomous-response questions (McMillan \& Schumacher, 2000). The researcher developed the questionnaire specifically for this study, by drawing from Saccardi's (1994) project on children's responses to books in general and Jordan and Purves' (1993) research on reader's responses to culturally diverse texts. Saccardi (1994) categorised children's evaluations of the books they had read or listened to, according to a framework that included the children's feelings about the books, their reasons for liking or disliking a book, what the books reminded them of, and their judgements of the books. Jordan and Purves (1993) examined the data obtained in their study according to a set of questions within four categories namely, expectations, judging, stereotyping, and interpreting. The present researcher generated questions for the questionnaire in this study by using Jordan and Purves' (1993) categories and Saccardi's (1994) framework. For example, under the category of judging, Saccardi, and Jordan and Purves looked at the reasons that participants gave for liking or disliking a text. The present researcher used this information to frame Questions i (What did you like about the story?) and 2 (What didn't you like about the story?) on the questionnaire. Questions 1 and 2 would, for example, elicit a descriptive response from the participants. The reasons for these responses would be explored further during the focus group interview in Phase 2.

\section{Procedure}

\section{Pilot phase}

Once ethical clearance was obtained from the University of Durban-Westville's Research Committee, a pilot phase was conducted. The aims were to familiarise the participants with the data collection procedure for Phases 1 and 2, and to determine whether they would be able to listen and attend for the duration of the session, to understand and complete the questionnaire, and to participate during a group interview. The researcher read an illustrated storybook titled 'Herb, the vegetarian dragon' to them. All 10 participants were able to concentrate adequately, to read and understand the questions and to record their answers in writing without any difficulty. The questionnaire was therefore not revised. Participants were also able to take turns when answering the researcher's questions during the group interview.

Phase 1. This phase consisted of four sessions, one for each folktale. During each video-recorded session, a different folktale was read aloud to the participants. Before reading the folktale to the participants, the researcher explained the vocabulary that may have been difficult or unfamiliar to them and answered any questions that they asked about the vocabulary. They were asked what their expectations were of the folktale, based on its country of origin. Thereafter, the folktale was read aloud and the participants were shown the illustrations at appropriate points in the story. The participants then gave written answers, via a questionnaire, about their responses to that folktale. The researcher read through each completed questionnaire once they were handed in and asked for clarification from respondents where necessary. This strategy was adopted as a form of 'member checking', which was used to enhance design validity (McMillan \& Schumacher, 2000). In addition, the use of the same data collection methods (viz. audio-visual recorded observation and self-administration of the questionnaire) on different occasions is a type of methodological triangulation used to verify the findings of the study. The transcribed data from the video-recordings and the completed questionnaires were analysed after each session. Based on the analysis of the data from the questionnaires and transcripts, the focus group interview schedule was constructed.

Phase 2. Using the focus group interview schedule (Appendix E), the researcher conducted the 60-minute interview with all ten participants. The session was video-recorded. The transcription of the interview was analysed.

Phase 3. The Russian and Chinese folktales were presented as planned during Phase 1. Participants were able to say what they would expect from these folktales. When the Czechoslovakian folktale was introduced to the participants, they did not know what to expect from such a folktale. Their uncertainty may have been due to their unfamiliarity with Czechoslovakia. The folktale was possibly "too distant" from their experiences. It was determined that, by this stage of the data collection, each participant appeared to be quite aware that folktales were inherent to all cultures and therefore might not be uncomfortable with an African folktale. Thus it was included in a Third phase 


\section{Data Analysis}

Multiple data sources were used, namely, transcribed data from the video-recordings of the story-telling sessions, written responses to the nine questions on the questionnaire; one completed questionnaire per participant for each of the five folktales, transcribed data from the video-recording of the focussed group interview, and the researcher's reflective journal and field notes. The presence of related themes in the data collected from multiple sources enhanced the credibility of the interpretation.

The method of constant comparison (McMillan \& Schumacher, 2000) was used to analyse the data. The first step in this process involved line-by-line coding, which entailed studying each line of the data and providing a topic or descriptive name. The second step involved focused coding, where the researcher chose a limited number of topics, which reappeared often in the initial line-by-line coding, and used these to sift through the data. By comparing and contrasting the topics, the researcher was able to organise the topics into categories and identify patterns of similarities among the categories (McMillan \& Schumacher). When identifying themes and subthemes in the data, 'member categories' and 'researcher categories' were used (McMillan \& Schumacher). Member categories represented the data from the participants' perspective while researcher categories represented the meaning of the phenomenon to the researcher (McMillan \& Schumacher).

\section{RESULTS AND DISCUSSION}

Five main themes were identified as follows.

- The family

- Retribution

- The influence of mass media on our cultural knowledge and worldviews

- Texts as 'mirrors'

- Children's views on the purposes of stories

As all the folktales focused on the broad theme of family relationships, the first theme emerged as a result of the nature or content of the folktales. The second to fourth themes represented re- searcher categories while the fifth theme was a member category derived directly from the participants' responses.

In the ensuing section, only two of the main themes, namely, 'the influence of the mass media on our cultural knowledge' and 'texts as mirrors', will be discussed. The reader is referred to Moodley (2003) for a detailed discussion of the other themes and related subthemes. The possible reasons for the participants' responses in relation to these two themes will be explored. In addition, the implications for future research and practice will be highlighted. Finally, the study will be critically evaluated.

\section{The Influence of the Mass Media on our Cultural Knowledge}

The participants' responses to the folktales underscored the powerful influence of the mass media on our cultural knowledge and views of the world. Participant VA (see Appendix A), for example, expected the Russian folktale to be about 'Red Indians' because the illustrations showed the characters wearing moccasins, clothing made from soft buckskin with fringes and beadwork, and feathers in their long, plaited hair. That is, they were dressed in a manner similar to the traditional portrayal of Native Americans in the mass media. Furthermore, the participants expected the Chinese folktale to be about martial arts, possibly because cinema and television tend to emphasise that aspect of Chinese culture.

Mass media has been cited as one of the ways in which children learn stereotypes and acquire cultural knowledge (Gay, 2002; Ford, 1999). For many learners, mass media is the sole source of information about cultural diversity and what is viewed on television is more striking and persuasive than what is discovered from books or classrooms (Gay, 2002). The participants' responses showed that there were several reasons why they preferred television as a source of information. Participants regarded television as more entertaining than books and believed that it gave one a 'better idea' or clearer picture of the culture and people. They stressed that the information conveyed on television was more memorable than that in books. The participants' responses in Table 1 further emphasise the persuasive influence of the mass media.

Table 1. The Influence of the Mass Media on Cultural Knowledge: Excerpt from the Focus Group Interview

\begin{tabular}{ll}
\hline RES: & Now if you spit in somebody's face it means...Do you know what it means? \\
ML: & Saying goodbye. Miss...because Miss I once watched a Jim Carey movie and when they greeted each other they spit at each other. \\
RES: & They did? Which country was the movie in? \\
ML: & I saw it on a Jim Carey movie one or two. \\
RES: & If it's a Jim Carey movie, do you think they really do things like that? \\
ML: & It's a culture Miss. It's a culture. \\
RES: & It's about a different culture? \\
VOICES: $\quad$ Yes, Miss. \\
RES: $\quad$ Which culture is this? \\
CE: $\quad$ They want to say hello. \\
RES: & By spitting? \\
CE: & $\quad$ Yes, Miss. (other participants said 'yes' in the background) \\
ML: & Because Miss, we can say hello and goodbye Miss, they can't \\
\hline
\end{tabular}

Note: The spitting incident occurred in the Russian folktale. The goldsmith spat in the Shaman's face to show his disgust at the Shaman's behaviour. RES $=$ Researcher 
Based on what he had seen in a movie, ML believed that spitting was a way of greeting and part of the 'culture' of the group portrayed in the movie (see Table 1 , lines $2 \& 6$ ). CE and the other participants agreed with ML (lines $10 \& 12$ ). These responses underscore the power of mass media, especially as the participants embraced what was seen in the movies as the truth. Similarly, Beach and Freedman's study (as cited in Benton, 1999) confirmed the tendency of learners to blur reality and fiction when discussing images portrayed in the mass media. Thus the messages transmitted via the mass media are extremely influential and should not be ignored as much of this information is inaccurate and often prejudicial (Gay, 2002). Other authors concur.

Banks (2001) has discussed how the mainstream media in the USA has controlled the construction of the Native American identity. It is important to remember that South African children are exposed to films that are produced mainly in the USA or the UK that reflect the values and perspectives of scriptwriters and producers from those societies. For example, even the popular animated film 'The Lion King', which might be regarded as an African story, was produced in the USA. One could therefore argue that the mainstream film and television media in the USA also exert a tremendous influence on South African society. VA's expectation that the Russian folktale would be about 'Red Indians' and the references to 'Jim Carey movies' in Table 1, illustrate this influence. These examples confirm the importance of media literacy within the RNCS, where the ability to recognise the influence of radio, television, film, and advertising on people and societies is an important Learning Outcome.

\section{Texts as Mirrors}

It was suggested earlier that cultural dissonance between the leaner and the text, for example, would present as a barrier to learning. Learners "need to locate themselves, their life and learning experiences, culture, values, language and physical characteristics within the books they are exposed to at school" in order for them to relate to school and the school culture (Taylor, 2001, p.24). This implies that texts must act as mirrors that reflect learners' lives. 'Several authors (Bieger, 1996; Cairney, 1995; Sims Bishop, 1992) have recognised the importance of literature as 'a mirror'. Those who see their own experiences reflected in literature or in texts are affirmed (Bieger, 1996; Sims Bishop, 1992). In exploring the importance of the text as mirror, the discussion will focus on the responses of participant NQ to the African folktale. NQ's response to this folktale was distinctive from her responses to the other folktales. The African folktale was the only one of the five folktales that she would recommend her friends to read.

It was evident from the researcher's analysis of the videorecordings, from comments recorded in the researcher's reflective journal, and from NQ's responses on the questionnaires, that NQ found most of the folktales uninteresting. On the video-recordings of Phase 1 NQ appeared distracted when the folktales were read out to the participants. She did not focus on the researcher while the story was read and would either shrug or smile when asked for her opinion during the discussions. The researcher, also observed these responses during the reading of the Cambodian folktale even though NQ described this folktale as 'not boring'. There was a noticeable difference in NQ's attentiveness and responsiveness to the African folktale (see Appendix $\mathrm{C}$ for a synopsis). At times, she leaned towards the researcher while listening and she provided a spontaneous verbal response for the first time (see Table 2, line 6), during the discussion of the African folktale.
Table 2.

Excerpt of Written and Spoken Responses to the African folktale

\section{Part A: Written responses to the question \\ 'How did the story make you feel? Why?'
CH:
Bored. No humour.
NI: Bored. Very bored. Because it was not interesting.
NQ: Happy. Because it was nice.
SN: Happy, 'cos it was exciting.
VA: Happy. It was nice and interesting.
Part B: Spoken responses
NQ:
It's nearly the same story. Cinderella also married the prince.
RES: Why did you think that story was 'nice'?
NQ: Because it was an African story.
RES: Was that because it had things that were familiar or because it was set in Africa?
NQ: It was set in Africa.
RES: VA, why did you think the story was nice?
VA: $\quad$ Because it was about a girl. I liked about Nyasha.

Note: $\mathrm{RES}=$ Researcher

It can be asserted that NQ responded positively to the African folktale because she was able to locate herself, her physical characteristics and language (Taylor, 2000) within the folktale. Jordan and Purves' (1993) research suggest that some learners were hesitant about entering the story realms of other cultures. In addition, they found that cultural differences between the leamer and the text also hampered the close identification of the leamer with the text. Thus one cannot ignore the possibility that the cultural distance between NQ and the first four folktales may have presented a barrier to her participating to a greater extent in the discussion of the folktales.

The participants' identities in terms of their gender, race, culture, family background (see Appendix A), and personalities, influenced their responses to the folktales. It is possible that NQ related to the main characters in the African folktale because they were female. This was VA's reason for liking the story (see Table 2 , line 12). The comments in Table 2 highlight that three of the five female participants in the study responded positively to the African folktale. These three participants (NQ, VA \& SN) were also the most similar to the main characters in terms of 'race' and home languages, which may have maximised their participation in the discussion. The results have gender implications as the text as mirror appeared to be of special significance to these three participants. Naidoo (1992) emphasised the need to create opportunities for girls' voices to be heard along with boys' voices. In a similar vein, the Department of Education (2002a) stresses that it is important to free the potential of girls and boys. It appears from the results that, by selecting texts that girls can identify with, one can create the impetus for them to participate more actively in the discussion of texts.

During the focus group interview CE stated that he found it difficult to understand "different things" and agreed that he pre- 
ferred stories about people who were similar to him. When children are allowed to choose texts independently, they tend to choose texts that reflect their own culture and interests, and are therefore familiar (Bieger, 1996). Other researchers have also discovered that learners preferred stories of their own culture (e. g. Altieri as cited in Webster, 2001). The Department of Education (2003) notes that issues of identity become increasingly significant to learners in the Intermediate Phase (Grades 4 - 7) and educators need to consider the relationship between language, culture and identity. Establishing a sense of personal identity is an important theme in children's lives. It has been suggested that each person has three identities (Locke, 1998). We have a global identity because all of us belong to the human race; a shared group identity as we belong to a cultural group or groups; and a unique personal identity as each of us differs from the other because of our unique experiences (Locke, 1998). It is important to be aware that membership of a cultural group impacts on personal identity (Locke, 1998), which may be why CE indicated a preference for stories about people who were similar to him.

\section{Implications for Future Practice and Research}

The Literacy Learning Programme is intended to create opportunities for each learner to understand and value their culture and identity, and that of others (Department of Education, 2003). Educators need to realise that the learning process is never value free. Power relations and ideology are ever present in the curriculum (Gay, 2002; Shor, 1999) and therefore to educate is to encourage learners in a given direction. This implies that as a facilitator of learning, one would need to discern when to accept learners' comments and when to explore their points of view. In addition, one would need to make learners aware that a point of view is not the truth, which is closely linked to facilitating the development of critical literacy and critical thinking. A strategy that would enable one to facilitate critical thinking amongst learners is an anti-bias approach to education. Such an approach promotes transformation, as there is increased awareness of how oppression and bias serve as barriers to learning (ELRC, 1997) for the learner and the educator.

Like all educators, the speech-language therapist needs to think carefully about the power that he or she has to influence the lives of learners. It is acknowledged that the speech-language therapist's focus on language learning and remediation through story reading is important. However, the discussion has focussed on how the types of Learning and Teaching Support Materials influence the response of the learner. The speech-language therapist therefore needs to have a broader focus and consider the impact that his or her choice of text has on the learner. NQ's responses to the African folktale in particular highlight this point. Learners are influenced by their literary experiences, which could provide educators with opportunities to nurture learners' selfesteem, cultural sensitivity and critical thinking. Educators need to lay the foundation skills for critical thinking during Grades 1 to 3. The speech-language therapist in schools and the teacher can begin this process by asking the right questions, such as Who is the story about? Whose point of view is reflected in the story?'

Educators are ultimately responsible for choosing texts and therefore need to be aware of the values portrayed in their choices. Texts used solely to promote language learning would still need the educator to determine if the chosen texts promoted negative stereotypes or affirmed some cultural groups at the expense of others. Such texts may create a barrier to learning for some learners. Some of the folktales that were selected for this study failed to capture the interest of the participants or to stimulate their active participation during the discussion. Not all participants responded in the same way and there needs to be an awareness of this level of diversity. An interesting area for further investigation would be learners' responses to other kinds of multicultural texts such as plays or poems. Such information would augment our knowledge of different multicultural Learning and Teaching Support Materials.

Some specch-language therapists and teachers may disagree with the need for a multicultural, anti-bias perspective.

However one must avoid the trap of believing that a multicultural perspective is only necessary when there is a diversity of learners in terms of race, culture or language. "An unbiased inclusive perspective can and should be present whether or not people of color are present" (Hooks as cited in Ford, 1999, p. 195). Change begins with the educator. Few educators have been trained to work with learners in a democratic style within multicultural and multilingual contexts (ELRC, 1997).

Most educators currently active in South African schools were taught within a system of apartheid education and were raised during a divided, oppressive, and authoritarian era. The educators' schooling and life experiences have impacted on their identities, perceptions and beliefs, and their assumptions about learners and about themselves. Consequently, "a conscious and definite strategy is required to bring about the paradigm shifts necessary to enable us to create a new society in which all differences and similarities amongst people are recognised, appreciated and drawn upon" (ELRC, 1997, p. 7). Every educator therefore should adopt an anti-bias approach to education. A further area of investigation would be to determine the type of facilitative skills that speech-language therapists and teachers require when using texts to promote critical literacy and critical thinking within an anti-bias approach.

Speech-language therapists also have a vital role to play in enabling LSEN in 'special schools', to achieve the same learning outcomes as learners in the mainstream learning context. Educators may believe that by focusing on the use of multicultural texts to foster critical literacy and critical thinking skills, the speech-language therapist would be trespassing on the domain of the teacher. Educators may believe that this is beyond the speechlanguage therapist's scope of practice because the speechlanguage therapist usually has focused on language-learning difficulties. However, in order for the changes mandated by Education White Paper 6 and the RNCS to be implemented successfully, all speech-language therapists and teachers need to consciously change their attitude towards their roles and responsibilities. Educators can no longer afford to work in isolation. Collaboration and consultation are crucial if speech-language therapists and teachers are to provide an equitable, inclusive and cost effective service (Department of Education, 2001) to all learners.

\section{A Critical Evaluation of the Study}

Every researcher has to make methodological choices when designing a research study. Two of the researcher's decisions may have constrained the results of the presént study. First, the decision to focus on 10-year old learners. within Grade 5 did not take into account that there are varying levels of ability amongst learners within the same age group and within a single grade (Department of Education, 2003). It may have been more appropriate to randomly select participants from all learners in the same grade, regardless of age. Such a decision also would 
have eliminated the possibility of teacher bias in identifying participants for the study. Teachers may have suggested names of learners whom they perceived as 'well-behaved' rather than 'troublesome' in class. Second, the researcher chose folktales that were written in English because English is the language of teaching and learning at the research site. However, seven of the participants spoke Zulu as their home language and English as their first additional language. Consequently, the use of English as the medium for the folktales, for the questionnaires, and for all spoken interactions, could have constrained the results. The participants' output, for example, may have been limited given that seven of them were responding in their additional language.

\section{CONCLUSIONS}

The following conclusions may be drawn from this study. Folktales that were set in ancient times and were not true to life were judged as boring by the participants. Such folktales appeared to be poorly matched to the interests and contemporary realities of 10-year old learners in Grade 5. However folktales that were filled with humour and action, or that mirrored aspects of the learners' lives or identities, were better able to capture their interest and stimulate their participation in the discussions.

The results of the study emphasise the importance of texts as mirrors. It was found that cultural distance between the learner and the text may hinder the learner's response to the text. All educators need to facilitate the full participation of all learners (Department of Education, 2003). From this study it can be concluded that one way of enhancing the potential of all learners, would be to ensure frequent opportunities for them to see themselves reflected positively in texts, balanced with texts that act as windows onto other peoples and worlds.

This study reflected the pervasive influence of the mass media on the learners' cultural knowledge and understanding of diversity. The messages conveyed in the mass media, especially television, appeared to be more potent than the information contained in books. There is a tendency for learners to blur reality/and fiction and to embrace what was depicted in the mass media as truth. Critical literacy and media critique are therefore crucial for all learners. The educator has an important role in facilitating the learner's enjoyment of and critical thinking about texts. A multicultural, anti-bias perspective is a crucial aspect of an educator's role as a facilitator of learning. Critical self-awareness by educators is an essential first step, with a pressing need for examination of their own biases, assumptions, and worldviews.

\section{Final Thoughts}

Multicultural literature or texts have considerable educational potential. However, it is in "the meeting of minds" between the educator and learner that this potential is fulfilled or unleashed (Naidoo, 1992, p. 138). Every speech-language therapist and teacher has to begin the essential process of change if they wish to be the kind of educator envisaged within the RNCS, to become lifelong learners, researchers, mediators of learning and "key contributors to the transformation of education in South Africa" (Department of Education, 2002a, p. 9). Only then can one aspire to the motto of "UNITY IN DIVERSITY' emblazoned on the, South African coat of arms.

\section{Acknowledgements}

This article is the culmination of a thesis submitted to the University of Durban-Westville (now the University of KwaZulu-Natal) by the first author, in partial fulfillment of the requirements for the degree Master of Communication Pathology (Speech-Language Pathology), under supervision of the second and third authors.

\section{REFERENCES}

Althanases, S.Z. (1998). Diverse learners, diverse texts: Exploring identity and difference through literary encounters. Journal of Literacy Research, 30(2), 273- 296. Retrieved June 20, 2002, from http://www.coe.uga.edu/jlr/v30/ article $3026 . \mathrm{html}$

Banks, J.A. (2001). Citizen education and diversity: Implications for teacher education. Journal of Teacher Education, 52 (1), 5-16.

Bass, J. (1999). Herb, the vegetarian dragon. Bath: Barefoot Books.

Benton, M. (1999). Readers, texts, contexts: Reader-response criticism. In P. Hunt (Ed.), Understanding children's literature (pp. 81-99). London: Routledge.

Bieger, E.M. (1996). Promoting multicultural education through a literature-based approach. The Reading Teacher, 4(4), 308-312.

Booysen, M. (1996). Creating literacy learning opportunities in the classroom. In P. Engelbrecht, S.M. Kriegler, \& M.I. Booysen (Eds.), Perspectives on learning difficulties: International concerns and South Africun realities (pp. 405421). Pretoria: J.L. van Schaik.

Cairney, T.H. (1995). Pathways to literacy. London: Cassell.

Chalk, G. (1984). Tales of Ancient China. London: Frederick Muller.

Champion, $\mathbb{T} . \mathbb{B} .$, Katz, $\mathbb{L} .$, Muldrow, $\mathbb{R}$., \& $\mathbb{D a i l}$, $\mathbb{R} .(1999)$. Storytelling and storymaking in an urban preschool classroom: Building bridges from home to school culture. Topics in Language Disorders, 19(3), 52-67.

$\mathbb{D}$ enzin, N.K., \& Lincoln, Y.S. (1998). Collecting and interpreting qualitative materials. California: Sage.

Department of Education. (2001). Education white paper 6. Special needs education: Building an inclusive education and training system. Pretoria: South African Department of Education.

Department of Education. (2002a). Revised National Curriculum Statement grades R-9 (schools) policy: Overview (English). Pretoria: South African Department of Education.

Department of Education. (2002b). Revised National Curriculum Statement grades R-9 (schools) policy: Languages (English-home language). Pretoria: South African Department of Education.

Department of Education. (2002c). Revised National Curriculum Statement grades R-9 (schools) policy: Languages (English-first additional language). Pretoria: South African Department of Education. 
Department of Education. (2003). Revised National Curriculum Statement grades R-9 (schools) teacher's guide for the development of learning programmes: Foundation phase. Pretoria: South African Department of Education.

Early Learning Resource Unit. (1997). Shifting paradigms: Using an anti-bias strategy to challenge oppression and assist transformation in the South African context. Cape Town: Early Learning Resource Unit.

Education Labour Relations Council. (2003). Policy handbook for educators. Pretoria: Education Labour Relation Council.

Ford, T. (1999). Becoming multicultural: Personal and social construction through critical teaching. New York: Falmer Press.

Galda, L., Ash, G.E., \& Cullinan, B.E. (2001). Research on children's literature. Reading Online, 4 (9). Retrieved March 16, 2002, from http://www. readingonline. org/ articles/artindex.asp?HREF=/articles/handbook/galda/ index.html

Gardner, $\mathbb{P}$. (2001). Teaching and learning in multicultural classrooms. London: David Fulton.

Gay, G. (2002). Preparing for culturally responsive teaching. Journal of Teacher Education, 53(2), 106-116.

Gillespie, C.S., Powell, J.L., Clements, N.E., \& Swearingen, R.A. (1994). A look at the Newberry Medal books from a multicultural perspective. The Reading Teacher, 48(1), 40-50.

Ho, M., \& Ros, S. (1995). The two brothers: A Cambodian folktale. London: Lothrop, Lee \& Shepard Books.

Jordan, S., \& Purves, A.C. (1993). Issues in the responses of students to culturally diverse texts: A preliminary study. National Center on Literature Teaching and Learning Report Series 7.3. Retrieved September 25, 2001, from http://cela.albany. edu/issrespon/index.html

Kavanagh, $\mathbb{K}$., \& Kennedy, $\mathbb{P}$. (1992). Promoting cultural diversity: Strategies for healthcare professionals. London: Sage.

Lemmer, A. (1988). Children's responses to literature. In I. Cilliers (Ed.), Towards understanding children's literature for Southern Africa (pp. 217-289). Cape Town: Maskew Longman Miller.

Lemmer, E.M. (1996). Selected linguistic realities in South African schools: Problems and perspectives. In P. Engelbrecht, S.M. Kriegler, \& M.I. Booysen (Eds.), Perspectives on learning difficulties: International concerns and South African realities (pp. 324-339). Pretoria: J.L.van Schaik.

Locke, D. (1992). Increasing multicultural understanding: A comprehensive model $\left(1^{\text {st }} \mathrm{ed}\right.$.). London: Sage.

Locke, D. (1998). Increasing multicultural understanding: A comprehensive model ( $2^{\text {nd }}$ ed.). London: Sage.

McMillan, J.H., \& Schumacher, S. (2000). Research in education: A conceptual introduction. New York: Longman.

Montgomery, W. (2001). Creating culturally responsive, inclusive classrooms. Teaching Exceptional Children, 33 (4), 4-9.
Moodley, S. (2003). The responses of ten-year old learners to folktales reflecting a diversity of cultures. Unpublished master's dissertation, University of KwaZulu-Natal, Durban, KwaZulu-Natal, South Africa.

Naicker, S.M. (1999). Curriculum 2002- a space for all: An introduction to inclusive education. Cape Town: Renaissance.

Naidoo, B. (1992). Through whose eyes? Exploring racism: Reader, text and context. Stoke-on-Trent: Trentham Books Limited.

Ngishkin, D. (1975). Folktales of the Amur: Stories from the Russian Far East. New York: Harry N. Abrams, Inc.

Nieto, S. (1996). Affirming diversity: The sociopolitical context of multicultural education ( $2^{\text {nd }}$ ed.). New York: Longman.

Outhwaite, W. (1994). Habermas: A critical introduction. Cambridge: Polity Press.

Owens, R.E. \& Robinson, L.A. (1997). Once upon a Time: Use of children's literature in the preschool classroom. Topics In Language Disorders, 17(2), 19-48.

Peters, A. (1994). Salt is sweeter than gold: An Eastern European folktale. Boston: Barefoot Books, Inc.

Pidgeon, N. (1996). Grounded theory: theoretical background. In J.T.E. Richardson (Ed.), Handbook of qualitative research methods for psychology and social sciences (pp. 74-85). Oxford: BPS Blackwell.

Rosenberg, $\mathbb{D}$. (1997). Folklore, myths, and legends: A world perspective. Lincolnwood: NTC Publishing Group.

Saccardi, M. (1994). Children speak: Our students' reactions to books can tell us what to teach. The Reading Teacher, 47 (4), 318-324.

Schultz, F. (1995). Preface. In F. Schultz (Ed.), Multicultural education 95/96 ( $2^{\text {nd }}$ ed.). Connecticut: The Dushkin Publishing Group.

Shor, 耳. (1999). What is critical literacy? Journal for Pedagogy, Pluralism \& Practice, 1 (4). Retrieved September 25, 2001, from http://www.lesley.edu/ journals/ippp/4/shor. htm\#do

Sims, R. (1983). Strong black girls: A ten-year-old responds to fiction about Afro-Americans. Journal of Research and Development in Education, 16(3), 21-28.

Sims Bishop, R. (1992). Children's books in a multicultural world: A view from the USA. In E. Evans (Ed.), Reading against racism (pp. 19-38). Buckingham: Open University Press.

Steptoe, J. (1987). Mufaro's beautiful daughters: An African tale. London: Hamish Hamilton.

Taylor, S.V. (2000). Multicultural is who we are: Literature as a reflection of ourselves. Teaching Exceptional Children, 32(3), 24-29.

Webster, J.W. (2001). Effects of ninth graders' culture-specific schemata on responses to multicultural literature. The Journal of Educational Research, 95(1), 12-25.

Willis, A.I. \& Johnson, J.L. (2000). A horizon of possibilities: A critical framework for transforming multiethnic literature instruction. Reading Online, 4(3). Retrieved April 16, 2001, from http://www.readingonline.org/articles/ art_index.asp?HREF=/ articles/willis/index.html 
The School-based Speech-Language Therapist: Choosing Multicultural Texts

\section{APPENDIX A}

\section{Description of participants}

\begin{tabular}{|c|c|c|}
\hline Participant & Family Structure/Religion & $\begin{array}{l}\text { Home languages/ } \\
\text { Gender }\end{array}$ \\
\hline $\mathbf{L I}$ & $\begin{array}{l}\text { Mother, father, } 2 \text { brothers, aunt, } 2 \text { cousins } \\
\text { - Christian }\end{array}$ & $\begin{array}{l}\text { Zulu; English used with brothers and cousins } \\
\text { male }\end{array}$ \\
\hline ML & $\begin{array}{l}\text { Mother, father, } 3 \text { brothers, } 2 \text { aunts, uncle, cousin } \\
\text { Christian/church-going }\end{array}$ & - $\quad \frac{\text { Zulu }}{\text { male }}$ \\
\hline $\mathbf{N Q}$ & $\begin{array}{l}\text { - Mother, father, } 2 \text { brothers, } 2 \text { sisters, aunt, uncle } \\
\text { Christian }\end{array}$ & $\begin{array}{l}\text { - Zulu; English } \\
\text { female }\end{array}$ \\
\hline MO & $\begin{array}{l}\text { - Mother, father, brother, } 2 \text { sisters } \\
\text { - Christian/church-going }\end{array}$ & $\begin{array}{l}\text { - Zulu; English used with older sister } \\
\text { male }\end{array}$ \\
\hline CE & $\begin{array}{l}\text { - Mother, sister, grandmother, aunt, uncle, } 6 \text { cousins } \\
\text { Christian }\end{array}$ & - $\quad$ Zulu; English \\
\hline NI & $\begin{array}{l}\text { - Mother, aunt, grandmother } \\
\text { - Christian }\end{array}$ & - $\frac{\text { English }}{\text { female }}$ \\
\hline TH & $\begin{array}{ll}\text { - } & \text { Mother, stepfather, step-brother } \\
\text { - Hindu }\end{array}$ & - $\quad$ English \\
\hline SN & $\begin{array}{l}\text { - Mother, father, sister } \\
\text { - Christian }\end{array}$ & $\begin{array}{l}\text { - Zulu; English } \\
\text { female }\end{array}$ \\
\hline $\mathbf{C H}$ & $\begin{array}{ll}\text { - Mother, sister } \\
\text { - Christian }\end{array}$ & - $\quad$ English; Afrikaans \\
\hline $\mathbf{V A}$ & $\begin{array}{l}\text { - Mother, father, sister, brother } \\
\text { - Christiạn }\end{array}$ & - $\frac{\text { Zulu }}{\text { female }}$ \\
\hline
\end{tabular}

\section{APPENDIX B}

\section{Criteria for selecting the folktales}

(Adapted from Gillespie, Powell, Clements, \& Swearingen, 1994; Sims Bishop, 1992)

- The culture and the characters should be portrayed as multifaceted, that is, strong three-dimensional characters.

- The cultural dimensions should be presented authentically.

- The folktale should not promote stereotypes.

- The language and dialect in the folktales should be presented authentically.

- The illustrations should contain authentic representations of scenes and people from the different cultural groups. Furthermore the illustrations should be attractive and able to capture and hold the attention of the target audience. 


\section{APPENDIX C}

\section{Synopsis of the African folktale 'Mufaro's beautiful daughters'}

This folktale is similar to the plot of Cinderella. It is about Mufaro's two daughters, Manyara and Nyasha. Manyara, who is vain, proud, and very jealous of her sister, pretends to be loving in front of Mufaro. Nyasha, by contrast, is genuinely industrious, kind and humble. The king wishes to marry one of them and asks Mufaro to choose which daughter should become the queen. However, Mufaro asks the king to make the decision. Manyara is determined to become queen and will do anything to be chosen. Using magical powers, the king tests the two sisters, without their knowledge, to determine who is worthy to be his wife. The folktale shows how Manyara's true character is revealed and how Nyasha is chosen to marry the king because of her gentleness and honesty.

Note: This folktale contained seventeen detailed full-page colour illustrations of all the significant details of the story.

\section{APPENDIX D}

\section{Questionnaire for Phase 1}

Please read this section and sign before answering the questions. I understand:

- What the study is about

- That all my details will be kept confidential.

Signed:

1. What did you like about the story?

2. What didn't you like about the story?

3. Was the story about what you expected?

4. What surprised you about the story?

5 . What did this story show you about people?

6. What did the story make you think about?

7a. How did the story make you feel? (For example: bored, sad, happy, confused, irritated, curious, angry)

7b. Why?

8a. Would you tell your friends to read this story?

8b. Why

9a. Was there anything that you did not understand?

9b. What was it?

\section{APPENDIX E}

\section{Focus Group Interview Schedule}

- Tell me what you thought of the folktales?

- How would you feel about reading other stories like this?

- If all the stories had been fun or enjoyable, which one best showed you about another culture?

- In what ways were the people in the stories just like you/different from you/your family/friends?

- How did you feel about a story when you thought that the people in the story were very different from you?

- How did you feel about the story when it was about a boy?

- How did you feel about the story when it was about a girl?

- How have the folktales changed your ideas about how people from other countries/race groups/ cultures could be different from you?

3 - In what ways did the stories make you think about how people are different or about how people are the same?

- How did the stories show you that people from another culture can have problems just like you?

- Would you like to read more books about people who are the same as you or people who are different from you, or both́?

- In what ways did the stories remind you of your own family/school/friends/home?

- What sort of books do you think should be in the library? What sorts of books don't we have enough of?

- In which/what ways have your experiences been similar to the experiences of the people in the story 


\section{INFORMATION FOR CONTRIBUTORS}

\section{NATURE OF PUBLICATION}

The South African Journal of Commiunication Disorders publishes reports and papers concerned with research, and critically evaluative theoretical and philosophical conceptual issues dealing with aspects of human communication and its disorders, service provision, training and policy.

The South African Journal of Communication Disorders will not accept material which has been published elsewhere or that is currently under review by other publications.

\section{MANUSCRIPT STYLE AND REQUIREMENTS}

\section{Preparation of manuscript}

Articles must he accompanied by a covering letter providing the author's address, telephone and fax numbers and e-mail address. Articles must be typed on A4 pages in double spacing and in a font size of 12

Three print outs of the article must be submitted.

ONE exact copy of the article on disk must be submitted. Filenames must include the first author's initials and a clearly identifiable key word and must he type-written on the last line of the last page of the Reference list (for retrieval purposes only).

Articles must not exceed 30 pages.

\section{Title page}

The title page of ONE must contain:

Title of the article.

Full names of the authors.

Institutional affiliation.

Abstract of the article in the language of the article.

The title page of the remaining TWO copies must NOT contain the authors' names or institutional affiliations.

\section{Abstracts and key words}

Each article must contain an abstract of no more than 200 words

All abstracts must be in ENGLISH, irrespective of the language in which the article was written.

Each article must provide 5-7 KEY WORDS for indexing purposes.

\section{Body of Article}

All contributions are required to follow strictly, the style specified in the Publication Manual of the American Psychological Association (APA Pub. Man., 2001).

- Headings are NOT NUMBERED. The order of importance is indicated as follows:

Main heading in capitals and bold print.

Sub-headings in upper and lower case, and bold print.

Sub-subheadings in upper and lower case bold and italic print.

- Sub-sub-sub-heading in upper and lower case and italic print.

Major headings, where applicable, must be in the order of INTRODUCTION, METHOD, RESULTS, DISCUSSION, CONCLUSION, ACKNOWLEDGEMENTS and REFERENCES.

All paragraphs should be indented.

\section{Tables, figures and illustrations}

All tables, figures and illustrations must he numbered and provided with titles.

The title of tables, which appear above, and of figures, which appear below, must he concise but explanatory.

Allow for $50-75 \%$ reduction in printing of tables, figures and illustrations.

Each table, figure or illustration must appear on a SEPARATE page and be print ready. Preferable NOT printed on colour printers.

Do not include more than 10 tables, figures or illustrations.

\section{REFERENCES}

References must he cited: in the text by surname of the author and the date, e.g., Van Riper (1971).

Where there are more than two authors, after the first occurrence, et al. may he used from the start.

The names of all authors must appear in the Reference List, which must he listed in strict alphabetical order in triple spacing at the end of the article.

All references must he included in the List, including secondary sources, (APA Pub. Man. 2001)

Only acceptable abbreviations of journals may be used, (see DSI1 ABSTRACTS, October; or The World List of Scientific Periodicals).

The number of references should not exceed much more than 30 , unless specifically warranted.

\section{Examples}

Locke, J.L. (1983). Clinical Psychology: The explanation and treatment of speech sound disorders. J. Speech Hear.Disord., 48: 339-341.

Penrod, J.P. (1985). Speech discrimination testing. In J. Katz (Ed.), Handbookofclinicalaudiology ( $3^{\text {rd }}$ ed.). Baltimore: Williams \& Wilkins.

Davis, G. \& Wilcox, M.J. (1985). Adult aphasia rehabilitation: Applied pragmatics. San Diego, CA: College-Hill.

\section{EDITING}

Articles must be revised for grammar and style prior to submission.

The manuscript style of the article must be strictly according to the guidelines provided.

Only articles complying with the above requirements will be accepted for review.

\section{REVIEWING SYSTEM}

The peer review of refereeing system is employed as a method of quality control of this publication.

Peer reviewers are selected by the editor based on their expertise in the field and each article is sent to two independent reviewers to assess the quality of the manuscript's scientific and technical content.

The blind peer review system is employed during which the names of the author/authors are not disclosed to the reviewers.

The editor retains the final responsibility for decisions regarding revision, acceptance or rejection of the manuscript.

\section{DEADLINE FOR CONTRIBUTIONS}

$30^{\text {th }}$ January each year.

\section{QUERIES, CORRESPONDENCE \& MANUSCRIPTS}

Address to: The Editor

South African Journal of Communication Disorders South African Speech-Language-Hearing Association P.O. Box 5710

THE REEDS

0158

South Africa

\section{Copyright}

The copyright of all articles printed in The South African Journal of Communication Disorders is reserved by The South African Speech-Language-Hearing Association (SASLHA). 